\title{
Organizational Citizenship Behaviors as Influenced by Supervisor Communication: The Role of Solidarity and Immediate Behaviors
}

\author{
Stephanie Kelly ${ }^{1}$, Laura Graham² ${ }^{2}$ Patrick MacDonald ${ }^{3}$, Ryan Goke ${ }^{4}$ \\ ${ }^{1}$ North Carolina A\&T State University, Greensboro, NC, USA \\ ${ }^{2}$ North Carolina Central University, Durham, NC, USA \\ ${ }^{3}$ Ecolab, St. Paul, MN, USA \\ ${ }^{4}$ Murray State University, Murray, KY, USA
}

Objectives: The purpose of this study was to assess the influence of supervisors' immediate behaviors and solidarity on subordinates' loyalty, obedience, and participation (i.e., organizational citizenship behaviors). A model was predicted in which supervisors' immediate behaviors and solidarity indirectly induced subordinates' organizational citizenship behaviors through the mediation of perceived immediacy.

Methods: Electronic questionnaires were disseminated through social media. A total of 228 participants completed the questionnaire, representing a variety of occupations and supervisor communicative styles.

Results: Each unidimensional measurement model was first subjected to a confirmatory factor analysis. The relationships between all variables were tested through Pearson correlations and were found to be both statistically significant and positive. Then, the data were analyzed through structural equation modeling. The data supported a path model in which perceived immediacy mediated supervisors' solidarity and immediate behaviors as influence of subordinates' loyalty. The mediation paths, however, were not supported for participation and obedience.

Conclusions: It is speculated that mediation was not observed in the obedience and participation paths because not engaging in these two organizational citizenship behaviors can have indirect consequences for subordinates, whereas loyalty is truly altruistic. It was concluded that supervisor solidarity and immediate behaviors can be practiced and refined to enhance the workplace climate, increasing loyalty in subordinates.

Key Words: Solidarity, Immediate Behaviors, Loyalty, Obedience, Participation

Received: Apr 20, 2018 Revised: Jun 25, 2018 Accepted: Jun 30, 2018

Corresponding author: Stephanie Kelly

North Carolina A\&T State University, 1601 E. Market Street, Greensboro,

NC 27411, USA

Tel: +1-336-285-4903, E-mail: sekelly@ncat.edu

This is an Open Access article distributed under the terms of the Creative Commons Attribution Non-Commercial License (http://creativecommons.org/licenses/ by-nc/4.0/) which permits unrestricted non-commercial use, distribution, and reproduction in any medium, provided the original work is properly cited.

Copyright $\odot 2018$ Korean Association for Business Communication.

\section{Introduction}

The importance of business communication training for the workplace as a force toward building productive organizational cultures is well supported (Beebe, Mottet, \& Roach, 2004). In fact, business communication training has become of such apparent importance that the Association to Advance Collegiate Schools of Business (AACSB) will not accredit any business 
program that does not show evidence of enhancing student oral and written communication skills (AACSB, 2013). The purpose of this paper is to better our understanding of the influence supervisor communication has on subordinates' workplace behaviors.

Two prominent variables in the communication literature have received very little attention in the business context: immediacy and solidarity. In the instructional communication literature, immediacy has been credited as the most powerful instructional communication variable (Kelly, Rice, Wyatt, Denton, \& Ducking, 2015). The potential communicative parallels from the teacher-student relationship to the supervisor-subordinate relationship are abundant. Like the supervisor-subordinate relationship, the instructor-student relationship has a power differential, in which the instructor, the communicator with more power, has the opportunity to use their communication to motivate, teach, inspire, and encourage the communicator in the position of less power; all of these are goals that instructors meet through the aid of immediate behaviors (Kelly et al., 2015; Kelly \& Westerman, 2016). Despite these parallels and the potential power of supervisor immediacy, perceived immediacy between supervisors and subordinates has been studied only once in the business setting (Kelly \& Westerman, 2014), in a study that sought to understand the relationship between supervisor immediacy and subordinate workplace behaviors.

Solidarity, likewise, is an influential communicative variable that has rarely been studied outside of the interpersonal context. Solidarity between communicators can develop trust (Wheeless, 1976, 1978), which is critical within a supervisor-subordinate relationship for subordinates to feel confident following a supervisor's lead. Despite this, only MacDonald, Kelly, and Christen (2014) and Kelly and MacDonald (2016) have looked at the effects of supervisor-subordinate solidarity, and again, these studies focused on resulting subordinate attitudes rather than behaviors.

Therefore, this paper will investigate the influence of supervisor immediate behaviors and solidarity on subordinate organizational citizenship behaviors, which include loyalty, participation, and obedience. It is anticipated that evidence will support a model in which perceived immediacy mediates the positive relationships between supervisors' communication (i.e., immediate behaviors and solidarity) and subordinates' organizational citizenship behaviors (i.e., loyalty, participation, and obedience).

\section{Solidarity}

Solidarity is an interpersonal phenomenon in which communication leads to a rapport between two individuals that is characterized by both synchronicity and trust (Wheeless,
1978). Solidarity has been defined in a number of ways, such as relationship intimacy (Baus \& Allen, 1996) and psychological closeness (Wheeless, 1978), and more specifically, has been described in terms of the quality of relationship, perceptions of closeness, and the presence of harmony and trust (Gremler \& Gwinner, 2000; Wheeless, 1976, 1978). MacDonald et al. (2014) explain that, "Solidarity can be conceptualized as an assessment of perceived rapport based on past communicative experiences, especially those involving self-disclosure" (p. 2).

Although solidarity has been studied mostly in the interpersonal context, it has also been demonstrated to influence the workplace. Itzkovich and Heilbrunn (2016) found that a lack of solidarity among co-workers was associated with increased workplace incivility, which led to increased deviant behavior toward the organization. MacDonald et al. (2014) and Kelly and MacDonald (2016), found that supervisor solidarity led to increased job satisfaction, which ultimately decreased subordinates' sense of burnout. Within the workplace, subordinates who perceive low solidarity with their supervisors have been observed to remain silent, particularly in terms of sharing negative feelings, for fear of political consequences (Diefendorff, Morehart, \& Gabriel, 2010; Milliken, Morrison, \& Hewlin, 2003; Sanders, Flache, van der Vegt, \& van de Vliert, 2006).

The dynamics of solidarity in supervisor-subordinate relationships are unique because supervisors' legitimate authority places them completely in control of the amount of formality or informality allowed into their relationships with subordinates (MacDonald et al., 2014; Sanders \& Schyns, 2006). This means that even if a subordinate desires to build solidarity, he or she cannot take the first steps to do this. Rather, subordinates must wait for their supervisor to decrease the formality of their interactions, allowing interpersonal conversation to take place. Therefore, assessment of how much solidarity a subordinate believes he or she has with his or her supervisor is an assessment of supervisor interpersonal communicative behaviors (Kelly \& MacDonald, 2016; MacDonald et al., 2014).

\section{Immediate Behaviors}

Another set of supervisor communicative behaviors that influence subordinates is immediate behaviors. Immediate behaviors were first identified by Mehrabian (1966) in clinical psychiatry who observed that psychiatrists who consistently experienced open communication with their patients engaged in the same set of nonverbal behaviors: forward lean, eye contact, attentive body orientation, openness of posture, light nonthreatening touch, limited physical distance, and relaxed posture (Mehrabian, 1981). He dubbed this group of nonverbal behaviors immediate behaviors, defining these behaviors as any communicative 
behavior that reduces perceived physical or psychological distance between communicators.

Later, immediate behaviors were investigated by communication scholars who observed these behaviors to follow the norm of reciprocity (Andersen, 1979; Coutts \& Schneider, 1976; Hale \& Burgoon, 1984; Jones \& Wirtz, 2007; Richmond \& McCroskey 2000; Roth \& Kuiken, 1975). Most research on immediate behaviors has been conducted in the classroom, investigating the influence of instructional immediacy on classroom outcomes. However, immediate behaviors have also been studied in organizations, where their use has implications for both supervisors and subordinates. Caldwell (1978) along with Porter, Wrench, and Hoskinson (2007) found a positive relationship between immediate supervisor behaviors and increased subordinate motivation. The use of supervisor immediate behaviors has also been shown to improve subordinates' job satisfaction (Kelly \& Westerman, 2014; Madlock, 2008) and reduce their burnout. Recently, Jia, Cheng, and Hale (2017) found that supervisor nonverbal immediate behaviors can influence subordinates' emotional experiences at work and help alleviate tension caused by emotional work, prompting employees to be more likely to stay with the organization.

\section{Perceived Immediacy}

Recent research on immediate behaviors has made a distinction between immediate behaviors and perceived immediacy (Kelly \& Westerman, 2016). As Mehrabian (1966) observed, immediate behaviors typically lead to a decrease in perceived psychological distance. This, however, is not always the case. For example, eye contact has been cited as an immediate behavior, which means that when a message sender makes eye contact with the message receiver, the receiver should feel closer to the sender. As immediate behaviors were conceptualized in the United States, however, they do not take into account the meaning other cultures place on these behaviors. Many Asian cultures use eye contact to covey intentional power (Kim \& Nam, 1998), which means that eye contact would increase, not decrease, psychological distance in some Asian countries. Likewise, eye contact could also increase psychological distance in the United States if the message receiver interpreted it as intimidating staring rather than casual eye contact. Therefore, the act of making eye contact is not the variable that changes perceived psychological distance. Instead, it is a message receiver's perception of that behavior that increases or reduces perceived distance. As such, the actual reduction in perceived physical and psychological distance is not immediate behaviors, but rather perceived immediacy (Kelly, 2012). In the one study to date which has considered the role of perceived immediacy in the workplace,
Kelly and Westerman (2014) found that perceived immediacy mediated the relationship between supervisors' immediate behaviors and subordinates' burnout in the United States.

\section{Organizational Citizenship Behaviors (OCB)}

OCB are defined as those behaviors an employee exhibits that go beyond basic job requirements (Alizadeh, Darvishi, Nazari, \& Emami, 2012; Smith, Organ, \& Near, 1983) and are evaluated as an extension or assumption of job performance (Borman \& Motowidlo, 1993; MacKenzie, Podsakoff, \& Fetter, 1993; Podsakoff, MacKenzie, Paine, \& Bachrach, 2000; Podsakoff, Whiting, Podsakoff, \& Blume, 2009; Pond, Nacoste, Mohr, \& Rodriguez, 1997; Rotundo \& Sackett, 2002). Graham (1991) explained that OCB span both in-role and extra-role behaviors, making OCB a second-order unidimensional construct reflected in loyalty, participation, and obedience. Loyalty involves commitment to the good of the organization through protection and volunteered extra effort (Van Dyne, Graham, \& Dienesch, 1994). Participation encompasses the authentic endorsement of and involvement in organizational governance as well as interest in the operation of the overall system. Finally, obedience is respect for the order, governance, and processes contained within the organization (Van Dyne et al., 1994).

Employees are driven to display OCB in anticipation of organizational gains (i.e., rewards, promotions, positive performance reviews; Organ \& Konovsky, 1989). Moideenkutty's (2006) research built on the theory of social exchange in relation to supervisor influence and subordinate' displays of OCB. In exchange, OCB improve the organizational culture. Employees who display OCB have higher job satisfaction (Alizade et al., 2012) and team commitment (Foote \& Tang, 2008). In a meta-analysis, Podsakoff et al. (2009) further identified that OCB related positively to organizational efficiency, productivity, and profitability.

The influence of leadership has been demonstrated to be an important predictor of OCB (Alizadeh et al., 2012). Madlock and Kennedy-Lightsey (2010) found that the satisfaction a subordinate had in communication with his/her subordinate was directly related to the amount of commitment displayed toward the organization. Furthermore, transformational leaders who clearly present an appropriate model, foster group goal achievement, and cognitively stimulate their subordinates are more likely to influence these same subordinates to display OCB (Alizadeh et al., 2012). Koster and Sanders (2006) further found that solidarity derived from a supervisor was correlated to generalized compliance gaining. Peelle (2007) also noted employees are likely to reciprocate support from their organization or supervisor with increased OCB. 
On the other hand, OCB can decrease when employees experience burnout or citizenship fatigue. Past studies have noted a correlation between increased feelings of burnout and decreased OCB (Cankir, 2017; Chiu \& Tsai, 2006; Liang, 2012; Talachi \& Gorgi, 2013). These studies have been conducted in various industries and cultural contexts, but all agree that employees who experience burnout decrease OCB. In fact, Liang (2012) asserted "...that OCBs are doomed if burnout is not managed appropriately" (p. 7).

\section{Model Proposal}

In short, past research has established that supervisors' immediate behaviors and solidarity positively influence subordinates' workplace mindset (Kelly \& Westerman, 2014; MacDonald et al., 2014). Research has also shown that message receivers do not respond directly to their message sender's communication but rather to their perception of that communication (Kelly \& Westerman, 2014; Kelly et al., 2015). As such, it is expected that supervisors' positive communicative behaviors (i.e., solidarity and immediate behaviors) will be positively related to perceived immediacy. Thus, the following hypotheses are proposed:

- Hypothesis 1: Immediate behaviors will be positively related to perceived immediacy.

- Hypothesis 2: Solidarity will be positively related to perceived immediacy.

Past research has also found strong relationships between subordinates OCB and burnout (Cankir, 2017; Chiu \& Tsai, 2006; Liang, 2012; Talachi \& Gorgi, 2013). Supervisors' solidarity and immediate behaviors have already been established as indirect influences of burnout. Therefore, it is possible that these variables also influence subordinates' OCB. If so, it should follow that subordinates do not respond directly to their supervisors' communicative behaviors but rather to their perceptions of those behaviors, meaning that the direct influence on sub- ordinates' OCB would be perceived immediacy. As such, the following hypotheses are also proposed:

- Hypothesis 3: Perceived immediacy will be positively related to loyalty.

- Hypothesis 4: Perceived immediacy will be positively related to obedience.

- Hypothesis 5: Perceived immediacy will be positively related to participation.

These hypotheses combine to form the model depicted in Figure 1.

\section{Methods}

\section{Subjects}

In total, $n=228$ subjects participated in this study. Among those subjects, 91 were male, 136 were female, and one chose not to disclose sex. Occupations of subjects broke down as follows: $31.1 \%$ military, $13.6 \%$ sales, $11.8 \%$ education, $8.8 \%$ skilled labor, $5.3 \%$ professional/managerial, $4.8 \%$ clerical, $2.2 \%$ factory, $1.3 \%$ transportation, and $20.6 \%$ other, with one participant choosing not to disclose his/her occupation. On average, subjects were $M=30.62(S D=10.99)$ years old and had worked at their job for $M=3.03(S D=4.58)$ years. Subjects were directed to respond to the questionnaire with their present supervisor in mind.

\section{Data Collection}

Once IRB approval was secured, subjects received a link through two of the researchers' Facebook timelines. Subjects saw the researcher's status, which invited U.S. citizens who were currently employed to complete a 15-minute questionnaire hosted by Qualtrics. It was necessary to limit this sample to U.S. citizens to ensure that only individuals born or who had lived in the U.S. for multiple years participated in this study; otherwise,

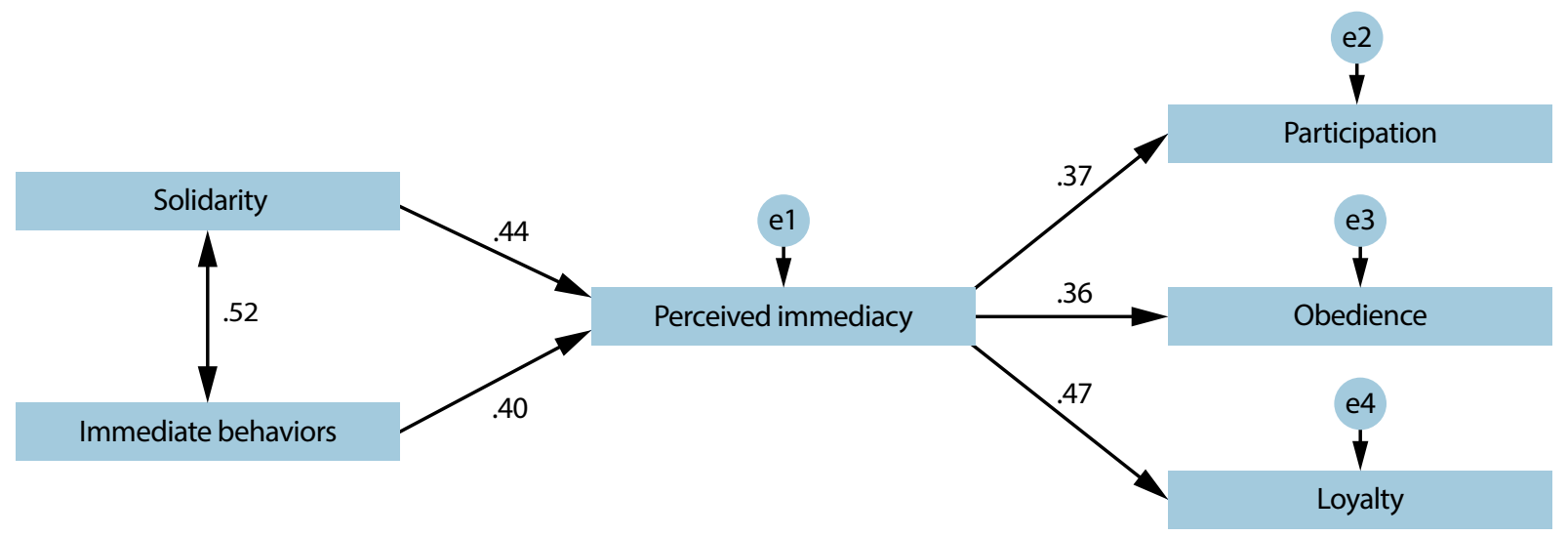

Figure 1. Observed Model (standardized effects). 
the immediate behaviors referenced in the immediate behaviors measure may not have been appropriate for all participants. This resulted in a $23 \%$ response rate with U.S.-based respondents. The link directed each subject to an informed consent page. Subjects were informed that they were giving their consent to participate in the study by clicking next. The informed consent described the study as an attempt to understand communication in the workplace. At the end of the questionnaire, they were given the option to enter a drawing for a $\$ 50$ gift certificate for their participation.

\section{Instrumentation}

The following sections detail the measures that were used for data collection. Each measure has been previously validated. Descriptive statistics for each measure are displayed in Table 1.

\section{Solidarity}

To assess supervisor-subordinate solidarity, MacDonald et al's (2014) adaption of Wheeless' (1976) revised Solidarity Scale was used. The measure was comprised of 12 items with a 7-point Likert-type response scale ranging from Disagree Strongly to Agree Strongly. MacDonald et al. (2014) reported that the measure showed evidence of content validity.

\section{Immediate Behaviors}

Immediate behaviors were assessed using an adapted version of McCroskey, Richmond, Sallinen, Fayer, and Barraclough's (1995) instructional immediacy measure. This assessment contained nine items with a seven-point Likert-type scale ranging from Disagree Strongly to Agree Strongly. The measure was adapted to reference a supervisor rather than an instructor. The same adaptation was used by Kelly and Westerman (2014), who reported the measure to have concurrent and content validity.

\section{Perceived Immediacy}

Kelly et al.s (2015) perceived immediacy measure was used. This measure consisted of 9 semantic differential items with a seven-point response range. The measure is reported to have strong content, divergent, and convergent validity.

\section{Organizational Citizenship Behaviors}

To assess organizational citizenship behaviors, Van Dyne et al's (1994) measure was utilized. This second-order unidimensional assessment consisted of three submeasures: loyalty (12 Likerttype items), obedience (11 Likert-type items), and participation (11 Likert-type items). Each item used a seven-point response scale ranging from Disagree Strongly to Agree Strongly. This measure is reported to have strong face and content validity (Van Dyne et al., 1994).

\section{Data Analysis}

A confirmatory factor analysis (CFA) was run on each unidimensional measurement model, which involved first a test of internal consistency and then parallelism. Measurement internal consistency considers how strongly each indicator correlates systematically with other indicators in that measure. Parallelism tests how strongly indicators purported to measure a different construct correlate systematically with indicators purported to measure the construct of interest. Thus, each unidimensional measurement model was first tested for internal consistency and parallelism issues.

The AMOS maximum likelihood parameter estimation algorithm was used to complete the CFA. This algorithm estimates factor loadings based on an a priori hypothesized measurement model. The algorithm uses derived factor loadings to generate the predicted inter-item correlation matrix used in internal consistency testing. The result is that items with obvious or subtle validity issues can be identified and then removed. Each time an item was removed from a measurement model, it was re-specified without the problematic items until all items causing a statistically significant amount of residual error were removed.

Pearson correlation coefficients were used to test each of the hypotheses. To test the model, structural equation modeling (SEM) was implemented using AMOS' maximum likelihood parameter estimation algorithm.

Table 1. Descriptive statistics

\begin{tabular}{lcccccc}
\hline Measure & Mean & SD & Min-Max & Skewness & Kurtosis & Cronbach's a \\
\hline Solidarity & 4.15 & 1.32 & $1.00-6.80$ & -.16 & -.71 & .89 \\
Immediate behaviors & 5.22 & 1.11 & $1.50-7.00$ & -.44 & -.19 & .75 \\
Perceived immediacy & 5.27 & 1.37 & $1.00-7.00$ & -.72 & .06 & .94 \\
Loyalty & 5.10 & .95 & $1.75-7.00$ & -.40 & .20 & .78 \\
Obedience & 5.79 & 1.05 & $2.00-7.00$ & -1.19 & -.18 & .88 \\
Participation & 5.25 & 1.04 & $1.75-7.00$ & -.29 & .12 & .85 \\
\hline
\end{tabular}




\section{Results}

\section{Measurement Models}

All problematic items were removed before hypothesis and model testing. Those items were identified by statistically significant standard residual errors (greater than 1.96 or less than -1.96). Items were removed one at a time, beginning with the item that yielded statistically significant residual error upon the most items, then the second most, and so forth. Two items were removed from the solidarity measure, three from immediate behaviors, three from the participation measure, two from the obedience measure, and three items from the loyalty measure. No items were lost in the perceived immediacy measure. Van Dyne et al.s (1994) OCD measure and McCroskey et al's (1995) immediate behaviors measure were constructed before CFAs were practiced by the social sciences to confirm content validity of measures. As such, it is not surprising that the measures lost more than one item. Fit statistics are presented in Table 2. Also, the appendix contains the retained items in each measure.

\section{Hypothesis Testing}

All five hypotheses were supported by Pearson correlation coefficients and their significances. The correlation matrix can be seen in Table 3.

Table 2. Fit statistics ( $\mathrm{N}=228)$

\begin{tabular}{lccc}
\hline Measure & \multicolumn{1}{c}{ Chi-square } & GFI & RMSEA \\
\hline Solidarity & $\chi^{2}(35)=94.03, p<.001$ & .92 & .09 \\
Immediate behaviors & $\chi^{2}(9)=30.53, p<.001$ & .96 & .10 \\
Perceived immediacy & $\chi^{2}(27)=79.31, p<.001$ & .93 & .09 \\
Loyalty & $\chi^{2}(27)=62.41, p<.001$ & .95 & .08 \\
Obedience & $\chi^{2}(27)=78.90, p<.001$ & .93 & .08 \\
Participation & $\chi^{2}(20)=42.83, p=.002$ & .95 & .07 \\
\hline
\end{tabular}

Note. GFI = goodness of fit index; RMSEA = root mean square error approximation.

\section{Model Testing}

The model predicted that a subordinate's perceived solidarity with his/her supervisor and the supervisor's immediate behaviors would induce perceived immediacy, which would in turn induce subordinate OCB (loyalty, obedience, and participation). The model had unsatisfactory fit statistics: $\mathrm{GFI}=.87$; $\mathrm{CFI}=.77$; RMSEA $=.21$; and $\chi^{2}(9)=99.33, p<.001$. As such, the model needed to be revised by removing paths with high residual error.

\section{Revised Model}

In the revised model, participation and obedience were removed because they were observed to cause a statistically significant amount of residual error in the first model test, primarily upon each other, and secondarily upon immediate behaviors. This revised model, shown in Figure 2, predicts that immediate behaviors and solidarity would positively induce perceived immediacy, which would positively induce loyalty. The revised model demonstrated good fit statistics: GFI $=.99$; $\mathrm{CFI}=1.00$; $\mathrm{RMSEA}=.04$; and $\chi^{2}(2)=2.86, p=.24$.

\section{Discussion}

As predicted, positive relationships were found between supervisors' use of immediate behaviors and solidarity, perceived immediacy, and subordinates' OCB. Although the relationships between immediate behaviors and perceived immediacy had been previously established in both the classroom and workplace setting (Kelly \& Westerman, 2014; Kelly et al., 2015), the correlation between perceived immediacy and solidarity is a new observation. In fact, the correlation between solidarity and perceived immediacy was the most robust of those calibrated within this dataset $(r=.65, p<.001)$. Immediate behaviors alone cannot explain all of the variance in perceived immediacy between communicators (Kelly, 2012). The implication of this moderate to strong correlation could be that the same reciprocal disclosure that forms solidarity (Wheelesss, 1978) and that

Table 3. Uncorrected correlation matrix

\begin{tabular}{|c|c|c|c|c|c|}
\hline Measures & Solidarity & Immediate behaviors & Perceived immediacy & Loyalty & Obedience \\
\hline Immediate behaviors & $p<.001$ & & & & \\
\hline Perceived immediacy & $p<.001$ & $\begin{array}{c}.63 \\
p<.001\end{array}$ & & & \\
\hline Loyalty & $\begin{array}{c}.38 \\
p<.001\end{array}$ & $p<.001$ & $\begin{array}{c}.47 \\
p<.001\end{array}$ & & \\
\hline Obedience & $p=.004$ & $\begin{array}{c}.31 \\
p<.001\end{array}$ & $\begin{array}{c}.36 \\
p<.001\end{array}$ & $\begin{array}{c}.50 \\
p<.001\end{array}$ & \\
\hline Participation & $\begin{array}{c}.38 \\
p<.001\end{array}$ & $\begin{array}{c}.34 \\
p<.001\end{array}$ & $\begin{array}{c}.37 \\
p<.001\end{array}$ & $\begin{array}{c}.57 \\
p<.001\end{array}$ & $\begin{array}{c}.58 \\
p<.001\end{array}$ \\
\hline
\end{tabular}




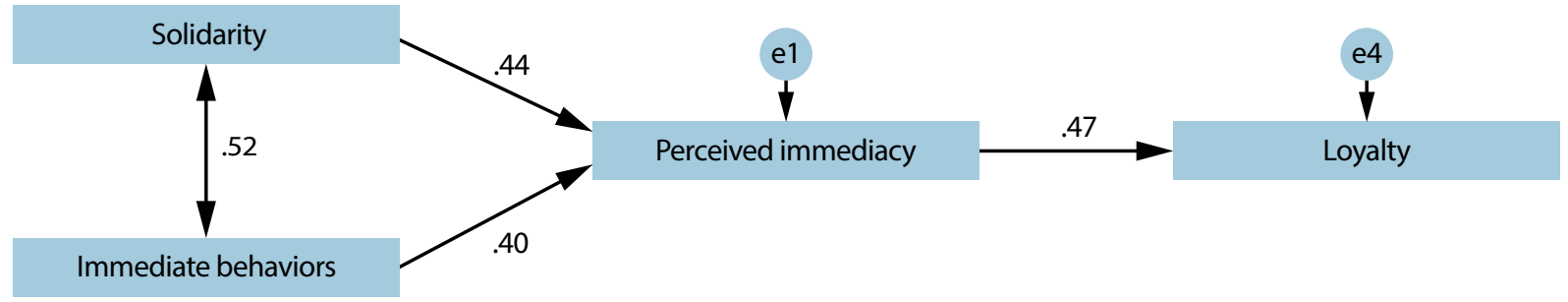

Figure 2. Supported Model (standardized effects).

is typically observed with the presence of immediate behaviors (Kelly, 2012; Mehrabian, 1966) explains more of the communicative tools a sender can use to influence the perceived immediacy felt by a message receiver.

Further, the data were consistent with a pattern supporting the notion that these supervisor communicative behaviors influenced loyalty indirectly through perceived immediacy. That perceived immediacy fit the data as a direct influence of loyalty is notable. This harkens to the findings of previous research in perceived immediacy (Kelly, 2012; Kelly \& Westerman 2014, Kelly et al., 2015), especially the experimental findings that manipulated the amount of immediate behaviors displayed, that message receivers are responding to their perceptions of communicators' behaviors, not the actual behaviors themselves.

In reference to the example provided in the literature review, supervisors need to ensure that if eye contact is an immediate behavior in the country in which they are working, that their eye contact is perceived as friendly and engaging rather than staring. This means that for supervisors to be effective, it does not matter how immediate they think they are or how much solidarity they think they have with subordinates; it is the subordinates' perceptions of those metrics that dictate their reactions. As such, supervisors who wish to be effective leaders need perceptual feedback from their subordinates. Supervisors should also be aware that not all subordinates will feel comfortable sharing such feedback directly and may need an anonymized way to give such feedback, such as a yearly evaluation, to feel safe being honest. Again, it does not matter whether supervisors think their subordinates should feel comfortable being honest; what matters is whether subordinates actually feel safe disclosing their opinions.

Although perception is key, the behavioral cues of immediacy and solidarity are still useful. Each culture has a set of immediate behaviors that are typically received positively by other communicators within that same culture. These behaviors can be practiced as a starting checklist for supervisors who wish to improve their communicative habits with subordinates (Kelly \& Westerman 2014, Kelly et al., 2015). Currently, there is no evidence that solidarity is culture specific, so informal disclosure may be a more universal behavior to promote perceived imme- diacy that can be used by supervisors. Given the role of OCB in a company's efficiency, productivity, and profitability (Podsakoff et al., 2009), it is critical that supervisors use all available tools to encourage their subordinates' OCB. The results of this study indicate that practicing such communicative behaviors may be particularly influential on subordinate loyalty.

It was surprising that the data did not support mediated relationships between supervisors' communication and subordinates' participation or obedience. This may be because loyalty is the only OCB that is truly altruistic. Participation involves endorsement of the company, and employees indirectly benefit from the positive promotion of their workplace (Van Dyne et al., 1994). As obedience involves withholding rhetorical dissent, though employees know they will not lose their jobs from engaging in disobedience, they may block their own potential promotion opportunities. Therefore, both obedience and participation have benefits for the company and the employee. Loyalty, however, involves commitment to the company through volunteering extra effort. There are no potential consequences for disloyalty, unlike lacking in participation (plateauing company growth) or obedience (plateauing one's own promotion potential). As such, it could be that subordinates will engage in those behaviors regardless of supervisors' communication to serve their own self-interest. However, loyalty is unselfish, so supervisors' communication can inspire this behavior in their subordinates.

Notably, this study was limited in that the data collection was questionnaire-based. SEM can be used to identify whether data patterns are consistent with causality, and this study relied upon causality observed in prior research to predict influence rather than manipulating the exogenous variables experimentally. As such, though the data imply that supervisor solidarity and immediate behaviors indirectly cause a change in subordinate loyalty, behavioral data is still needed to verify this.

Future research may also consider testing this model outside of the U.S. The vast majority of organizational communication research relies upon data collected within the U.S. and East Asian cultures. Again, although perceived immediacy is a psychological construct that spans cultural groups, the behaviors that induce perceived immediacy are not. Researchers are thus 
cautioned to use an immediate behavior measure validated in the target culture of interest.

Future research should also consider the potential moderating effect of supervisors' leadership styles on OCB. Prior research has identified that an authoritarian leadership style lacks the two-way communication necessary to develop solidarity (Kelly \& MacDonald, 2016). As such, it is possible that leadership style would moderate the model supported by this data.

\section{Conclusion}

The data collected for this study show that in the presence of supervisor solidarity and immediate behaviors, subordinates display higher loyalty. Loyalty, as well as the other OCBs, is a direct benefit to any organization. As such, supervisors can benefit from practicing communicating with immediate behaviors and to form solidarity. Supervisors should also remember, however, that subordinates do not respond directly to their communicative behaviors, but rather to their impressions of those behaviors (Kelly \& Westerman, 2014). As such, supervisors who wish to improve their communication practices would benefit from allowing anonymous assessments of their communication styles by subordinates.

\section{References}

AACSB [Association to Advance Collegiate Schools of Business]. (2013). Eligibility procedures and accreditation standards for business accreditation. Retrieved from http://www.aacsb.edu/ accreditation/business/standards/2013/2013-business-standards. pdf

Alizadeh, Z., Darvishi, S., Nazari, K., \& Emami, M. (2012). Antecedents and consequences of organisational citizenship behaviors (OCB). Interdisciplinary Journal of Contemporary Research in Business, 3(9), 494-505.

Andersen, J. F. (1979). Teacher immediacy as a predictor of teaching effectiveness. Communication Yearbook, 3(1), 543-559.

Baus, R. D., \& Allen, J. R. (1996). Solidarity and sexual communication as selective filters: A report on intimate relationship development. Communication Research Reports, 13(1), 1-7.

Beebe, S. A., Mottet, T. P., \& Roach, K. D. (2004). Training and development: Enhancing communication and leadership skills. Boston, MA: Allyn \& Bacon.

Borman, W. C., \& Motowidlo, S. M. (1993). Expanding the criterion domain to include elements of contextual performance. In $\mathrm{N}$. Schmitt, W. C. Borman, \& Associates (Eds.), Personnel selection in organizations (pp. 71-98). San Francisco, CA: Jossey-Bass.

Caldwell, D. (1978). Employee motivation under merit systems. Public Personnel Management, 7(1), 65-71.
Cankir, B. (2017). The effect of burnout on the organizational citizenship behavior among Academicians. Çanakkale Onsekiz Mart University Journal of Management Science, 15, 193-209.

Chiu, S. F., \& Tsai, M. C. (2006). Relationships among burnout, job involvement, and organizational citizenship behavior. The Journal of Psychology, 140(6), 517-530.

Coutts, L. M., \& Schneider, F. W. (1976). Affiliative conflict theory: An investigation of the intimacy equilibrium and compensation hypothesis. Journal of Personality and Social Psychology, 34(6), 1135-1142.

Diefendorff, J., Morehart, J., \& Gabriel, A. (2010). The influence of power and solidarity on emotional display rules at work. Motivation and Emotion, 34(2), 120-132.

Foote, D. A., \& Tang, T. L. (2008). Job satisfaction and organizational citizenship behavior (OCB): Does team commitment make a difference in self-directed teams? Management Decision, 46(6), 933-947.

Graham, J. W. (1991). An essay on organizational citizenship behavior. Employee Responsibilities and Rights Journal, 4(4), 249-270.

Gremler, D. D., \& Gwinner, K. P. (2000). Customer-employee rapport in service relationships. Journal of Service Research, 3(1), 82-102.

Hale, J. L., \& Burgoon, J. K. (1984). Models of reactions to changes in nonverbal immediacy. Journal of Nonverbal Behavior, 8(4), 287-314. Itzkovich, Y., \& Heilbrunn, S. (2016). The role of co-workers' solidarity as an antecedent of incivility and deviant behavior in organizations. Deviant Behavior, 37(8), 861-876.

Jia, M., Cheng, J., \& Hale, C. L. (2017). Workplace emotion and communication: Supervisor nonverbal immediacy, employees' emotion experience, and their communication motives. Management Communication Quarterly, 31(1), 69-87.

Jones, S. M., \& Wirtz, J. G. (2007). "Sad monkey see, monkey do:” Nonverbal matching in emotional support encounters. Communication Studies, 58(1), 71-86.

Kelly, S. E. (2012). Examining the role of perceived immediacy as a mediator: Revisiting the relationships among immediate behaviors, liking, and disclosure (Doctoral dissertation). University of Tennessee, Knoxville, TN.

Kelly, S., \& MacDonald, P. (2016). A look at leadership styles and workplace solidarity communication. International Journal of Business Communication. doi:10.1177/2329488416664176

Kelly, S., Rice, C., Wyatt, B., Ducking, J., \& Denton, D. (2015). Teacher immediacy and decreased student quantitative reasoning anxiety: The mediating effect of perception. Communication Education, 64(2), 171-186.

Kelly, S., \& Westerman, C. Y. K. (2014). Immediacy as an influence on supervisor-subordinate communication. Communication Research Reports, 31(3), 252-261.

Kelly, S., \& Westerman, D. K. (2016). New technologies and distributed learning systems. In P. L. Witt (Ed.), Handbooks of communication science (Vol. 16): Communication and learning (pp. 455- 
480). Berlin, Germany: DeGruyter Mouton.

Kim, J. Y. \& Nam, S. H. (1998). The concept and dynamics of face: Implications of organizational behavior in Asia. Organizational Science, 9(4), 522-534.

Koster, F., \& Sanders, K. (2006). Organisational citizens or reciprocal relationships? An empirical comparison. Personnel Review, 35(5), 519-537.

Liang, Y. W. (2012). The relationships among work values, burnout, and organizational citizenship behaviors: A study from hotel front-line service employees in Taiwan. International Journal of Contemporary Hospitality Management, 24(2), 251-268.

MacDonald, P., Kelly, S., \& Christen, S. (2014). A path model of workplace solidarity, satisfaction, burnout, and motivation. International Journal of Business Communication. doi:10.1177/2329488414525467

MacKenzie, S. B., Podsakoff, P. M., \& Fetter, R. (1993). The impact of organizational citizenship behavior on evaluations of salesperson performance. Journal of Marketing, 57(1), 70-80.

Madlock, P. E. (2008). Employee satisfaction: An examination of supervisors' communication competence. Human Communication, 11(1), 87-100.

Madlock, P. E., \& Kennedy-Lightsey, C. (2010). The effects of supervisors' verbal aggressiveness and mentoring on their subordinates. Journal of Business Communication, 47(1), 42-62.

McCroskey, J. C., Richmond, V. P., Sallinen, A., Fayer, J. M., \& Barraclough, R. A. (1995). A cross-cultural and multi-behavioral analysis of the relationship between nonverbal immediacy and teacher evaluation. Communication Education, 44(4), 281-291.

Mehrabian, A. (1966). Immediacy: An indicator of attitudes in linguistic communication. Journal of Personality, 34(1), 26-34.

Mehrabian, A. (1981). Silent messages (2nd ed.). Belmont, CA: Wadsworth Publishing Co.

Milliken, F. J., Morrison, E. W., \& Hewlin, P. F. (2003). An exploratory study of employee silence: Issues that employees don't communicate upward and why. Journal of Management Studies, 40(6), 1453-1476.

Moideenkutty, U. (2006). Supervisor downward influence and supervisor-directed organizational citizenship behavior. Journal of Organizational Culture, Communication and Conflict, 10(1), 1-9.

Organ, D. W., \& Konovsky, M. A. (1989). Cognitive versus affective determinants of organizational citizenship behavior. Journal of Applied Psychology, 74(1), 157-164.

Peelle, H. E. (2007). Reciprocating perceived organizational support through citizenship behaviors. Journal of Managerial Issues, 19(4), 554-575.

Podsakoff, P. M., MacKenzie, S. B., Paine, J. B., \& Bachrach, D. G. (2000). Organizational citizenship behaviors: A critical review of the theoretical and empirical literature and suggestions for future research. Journal of Management, 26(3), 513-563.

Podsakoff, N. P., Whiting, S. W., Podsakoff, P. M., \& Blume, B. D. (2009). Individual- and organizational-level consequences of organizational citizenship behaviors: A meta-analysis. Journal of Applied Psychology, 94(1), 122-141.

Pond, S. B., Nacoste, R. W., Mohr, M. F., \& Rodriguez, C. M. (1997). The measurement of organizational citizenship behavior: Are we assuming too much? Journal of Applied Social Psychology, 27(17), 1527-1544.

Porter, H., Wrench, J. S., \& Hoskinson, C. (2007). The influence of supervisor temperament on subordinate job satisfaction and perceptions of supervisor sociocommunicative orientation and approachability. Communication Quarterly, 55(1), 129-153.

Richmond, V. P., \& McCroskey, J. C. (2000). The impact of supervisor and subordinate immediacy on relational and organizational outcomes. Communication Monographs, 67(1), 85-95.

Roth, M., \& Kuiken, D. (1975). Communication immediacy, cognitive compatibility and immediacy of self-disclosure. Journal of Counseling Psychology, 22(2), 102-107.

Rotundo, M., \& Sackett, P. R. (2002). The relative importance of task, citizenship, and counterproductive performance to global ratings of job performance: A policy-capturing approach. Journal of Applied Psychology, 87(1), 66-80.

Sanders, K., Flache, A., van der Vegt, G., \& van de Vliert, E. (2006). Employees' organizational solidarity within modern organizations: A framing perspective on the effects of social embeddedness. In D. Fetchenhauer, A. Fleche, A. Buunk, \& S. Lindenberg (Eds.), Solidarity and prosocial behavior: An integration of sociological and psychological perspectives (pp. 141-156). New York, NY: Springer.

Sanders, K., \& Schyns, B. (2006). Leadership and solidarity behavior: Consensus in perception of employees within teams. Personnel Review, 35(5), 538-556.

Smith, C. A., Organ, D. W., \& Near, J. P. (1983). Organizational citizenship behavior: Its nature and antecedents. Journal of Applied Psychology, 68(4), 653-663.

Talachi, R. K., \& Gorji, M. B. (2013). Evaluating the relationship between job burnout and organizational citizenship behavior: A study of industry, mine and trade organization employees. Arabian Journal of Business and Management Review, 2(8), 50-61.

Van Dyne, L., Graham, J. W., \& Dienesch, R. M. (1994). Organizational citizenship behavior: Construct redefinition, measurement, and validation. Academy of Management Journal, 37(4), 765-802.

Wheeless, L. R. (1976). Self-disclosure and interpersonal solidarity: Measurement, validation, and relationships. Human Communication Research, 3(1), 47-61.

Wheeless, L. R. (1978). A follow-up study of the relationships among trust, disclosure, and interpersonal solidarity. Human Communication Research, 4(2), 143-157. 